\title{
Prevalence of Gastric Cancers among Patients Undergoing Upper Gastrointestinal Endoscopies in a Tertiary Care Hospital in Nepal: A Descriptive Cross-sectional Study
}

\author{
Subash Bhattarai, ${ }^{1}$ Merina Gyawali, ${ }^{2}$ Sudeep Regmi ${ }^{3}$ \\ 'Department of Medicine, Manipal College of Medical Sciences and Teaching Hospital, Pokhara, Nepal, \\ 2Department of Radiodiagnosis and Imaging, Manipal College of Medical Sciences and Teaching Hospital, Pokhara, \\ Nepal, ${ }^{3}$ Department of Pathology, Manipal College of Medical Sciences and Teaching Hospital, Pokhara, Nepal.
}

\section{ABSTRACT}

Introduction: Gastric cancer is a common malignancy of the upper gastrointestinal (UGI) tract. Gastric cancer is a common cause of death worldwide. This research aimed to study the prevalence of gastric cancer among patients undergoing upper gastrointestinal endoscopies.

Methods: A descriptive, cross-sectional study was conducted in the Department of Medicine at Manipal Teaching Hospital, Nepal, from January 2018 to June 2020. A total of 2640 subjects underwent upper gastrointestinal endoscopies over the study period. Ethical approval was taken from the institutional review committee of Manipal College of Medical Sciences (MEMG/ IRC/ 383/ GA). Data were analyzed by SPSS version 20.

Results: The prevalence of gastric cancer among patients undergoing UGI endoscopies was $2.4 \%$. The mean age of subjects was $58 \pm 12.35$ years (range of 31 to 96 years) with male predominance (M: $\mathrm{F}=1.9: 1)$. Antrum was the most common site for gastric carcinoma. The most common morphology was ulcerative growth (46.9\%). Adenocarcinoma (98.4\%) was the most common histology, and the majority was of intestinal subtype (56.3\%).

Conclusions: Gastric cancer is not an uncommon finding in patients undergoing UGI endoscopies. Gastric cancers were commonly seen above 50 years of age and predominant in males. Patients with gastric carcinoma usually present late with advanced disease stages and unfavorable histopathology

Keywords: adenocarcinoma; endoscopy; gastric cancer; histopathology.

\section{INTRODUCTION}

Cancer is one of the most dreaded non-communicable diseases that have become an important contributor to disease's global burden. ${ }^{1}$ The gastrointestinal (GI) cancers are responsible for more cancers and more deaths from cancer than any other cancers. ${ }^{2}$ Gastric cancers is the commonest upper gastrointestinal (UGI) malignancy and is the second most common cause of death worldwide. ${ }^{3}$

A high incidence of gastric cancer has been reported from Southeast Asia attributed to the high consumption of preserved food containing carcinogenic nitrates. ${ }^{4}$ Endoscopy followed by endoscopic biopsy is a very useful diagnostic tool for pathologies of the upper GI tract, including gastric cancers. ${ }^{5}$
National data on the demographic profile of stomach cancers are scanty. This research is meant to study gastric cancer prevalence among patients undergoing UGI endoscopies attending medical gastroenterology clinic at a tertiary care Teaching Hospital in Gandaki province, Nepal.

\section{METHODS}

This was a hospital-based, observational, crosssectional, retrospective study carried out in the

Correspondence: Dr. Subash Bhattarai, Unit of Gastroenterology, Department of Medicine, Manipal College of Medical Sciences and Teaching Hospital, Pokhara, Nepal. Email: kiwisubash@yahoo.com, Phone: +977-9815293117. 
unit of Medical Gastroenterology, Department of medicine at Manipal College of Medical Sciences and Teaching Hospital, Nepal, from January 2018 to June 2020 for a period of $\mathbf{3 0}$ months. The Institutional Review committee of the Manipal College of Medical Sciences approved the study (MEMG/IRC/383/GA/26th Aug 2020). The sample size was collected using the formula,

$\mathrm{n}=\mathrm{Z}^{2} \mathrm{pq} / \mathrm{e}^{2}$

Where,

$$
\begin{aligned}
& \mathrm{Z}=1.96(\text { at } 95 \% \text { confidence interval) } \\
& \mathrm{p}=\text { taking } 50 \% \\
& \mathrm{e}=\text { margin of error }, 5 \%
\end{aligned}
$$

The calculated minimum sample size was 385 .

Cases from January 2018 to June 2020 were studied from the records of the Endoscopy unit, departmental admission, and discharge summaries. All consecutive cases of 18 years and above who presented to the Medical Gastroenterology unit (under the department of medicine) either as outpatients or in patients who underwent upper GI endoscopy were enrolled for the study. Patients already diagnosed with gastric carcinoma or those with no histopathological confirmation or those with incomplete records, those with primary gastric lymphoma, gastrointestinal stromal tumor, and neuroendocrine tumor were excluded from the study. Studied variables include endoscopic findings, sites of lesions, and histopathological subtypes.

Contrast-Enhanced Computed Tomography ( PHILIPS Ingenuity 128 CT Scanner, NETHERLANDS Inc) scan of the abdomen and pelvis was done to complete the evaluation of upper Gl tract and study of regional lymphadenopathies, ascites, and metastases. After hemodynamic stabilization, overnight fasting and premedications, and informed consent, an endoscopy (PENTAX EPK 700, PENTAX JAPAN Inc) was performed. Endoscopy findings were noted. At least 4 tissue biopsies were taken from the nonnecrotic gastric pathological site in $10 \%$ formalin and sent to the pathology department for histological assessment. The histologic tumor type of gastric cancer (GC) was classified according to the Lauren classification. (Intestinal, diffuse, and mixed type). The microscopes used were Carl Ziess Axiostar Plus and Olympus CX21. Endoscopy findings with biopsies from the suspected sites followed by histopathology were all helpful in the diagnosis of gastric cancer.

Data collected were collected in a preformed sheet. Data were entered in Microsoft Excel 2010 and analysis was done using SPSS version 20. All categorical data were expressed in percentage and absolute number. All continuous numerical data were expressed in mean \pm SD. All tests were analyzed with a $95 \%$ confidence interval.

\section{RESULTS}

A total of 2640 subjects underwent upper Gl endoscopies over the study period of 30 months. Sixty-four patients were detected with gastric cancer, demonstrating a prevalence of $2.4 \%$ among patients undergoing UGI endoscopies. The study group comprised of $42(65.6 \%)$ males and 22 (34.4\%) females ( $\mathrm{M}: \mathrm{F}=1.9: 1)$. The mean age of subjects was $58 \pm 12.35$ years with a range of 31 - 96 years of age. Four (6.2\%) patients were aged below 40 years of age. Patients were classified as per age group (Table 1). A majority $(n=36 ; 56.25 \%)$ of cases were aged between 51 and 70 .

\begin{tabular}{|lll|}
\hline $\begin{array}{l}\text { Table 1. Age groups distribution of gastric carcinoma } \\
\text { ( } \mathbf{n = 6 4 )} .\end{array}$ & \\
\hline Age Groups & Numbers & Frequency $(\%)$ \\
$\leq 50$ years & 12 & 18.75 \\
$51-70$ years & 36 & 56.25 \\
$>71$ years & 16 & 25 \\
Total & 64 & 100 \\
\hline
\end{tabular}

UGI Endoscopy revealed that antrum (48.4\%) was the commonest site of gastric carcinoma. The other locations were as in Table 2. Gastric carcinoma were observed commonly with ulcerative lesions $(n=30$; $46.9 \%$ ), followed by ulceropoliferative ( $n=24,37.5 \%$ ) and proliferative growth ( $n=10 ; 15.6 \%)$.

\begin{tabular}{|lcc|}
\hline \multicolumn{3}{|c|}{ Table 2. Distribution of Gastric carcinoma $(\mathbf{n}=\mathbf{6 4})}$. \\
\hline Site & Numbers & Frequency (\%) \\
Antrum & 31 & 48.4 \\
Antrum + Body & 15 & 23.4 \\
Body & 10 & 15.6 \\
Body + Fundus & 5 & 7.8 \\
Fundus & 3 & 4.7 \\
TOTAL & 64 & 100 \\
\hline
\end{tabular}

CECT of the abdomen revealed findings suggestive or suspicious of gastric malignancies in 46 (71.8\%) patients. CT revealed mild to moderate ascites in 12 $(18.7 \%)$ cases. The liver was the most common site of metastasis found in 16 (25\%) patients, followed by left supraclavicular lymph node (12.6\%), peritoneal metastasis $(10 \%)$, and multiple metastases $(8.1 \%)$. Majority, 30 (46.8\%) of these patients presented with Stage III carcinoma followed by stage IV ( $n=16 ; 25 \%)$, stage II $(n=12 ; 18.8 \%)$ and Stage I ( $n=6 ; 9.4 \%)$.

After the endoscopic biopsy, the most common histology was adenocarcinoma seen in 63 (98.4\%), followed by a single (1.6\%) adenosquamous carcinoma case. Among the adenocarcinomas, 36 (56.3\%) were 
intestinal type, $16(25 \%)$ were diffuse, and the rest, 12 $(18.7 \%)$, were mixed adenocarcinoma. Most $(n=22 ; 61.1$ $\%)$ of the intestinal carcinoma were well to moderately differentiated whereas, most of the diffuse or mixed type tumors were poorly differentiated $(n=20 ; 71.4 \%)$.

\section{DISCUSSION}

In the current study, the prevalence of gastric cancer among patients undergoing UGI endoscopies was $2.4 \%$. In a previous Nepalese study from this region in 2013 comprising of 2820 endoscopies by Shrestha et al. ${ }^{6}$, gastric carcinoma prevalence was reported to be $1.8 \%$. The prevalence or detection of gastric cancer may be rising every year in this region.

The mean age of subjects was $58 \pm 12.35$ years with male predominance (M: $\mathrm{F}=1.9: 1)$. Majority (56.3\%) of cases were aged between 51-70 years of age. In a previous Nepalese study by Ghosh et al. ${ }^{7}$, gastric tumors were seen even more (83\%) in the same age group of 51-70. The mean ages were 57, 54, 54, and 51 years by Das et al. ${ }^{8}$, Cherian et al. ${ }^{9}$, Debbarma et al. ${ }^{10}$, and Kabir et al. ${ }^{11}$, respectively. These studies have mentioned that gastric carcinoma is commonly observed between 50 and 60 years of age with male predominance. In the current study, $6.2 \%$ of patients were aged below 40 years of age. In a study in Vietnam by Quach et al. ${ }^{12}$, gastric cancer incidence in young below 40 years of age was even higher (16.3\%). So, this cancer is not only restricted to the elderly.

Antrum (48.4\%) was the commonest site of gastric carcinoma, followed by carcinoma of the body in the current study. Antrum was similarly found to be the most common site of carcinoma according to Ghosh et al. ${ }^{7}(70 \%)$, Mir et al. ${ }^{13}(57.52 \%)$, Barad et al. ${ }^{14}$ $(50.6 \%)$, Saha et al.15 (51.9\%), and Kabir et al. ${ }^{11}$ (50\%). In the current study, gastric carcinoma was observed commonly with ulcerative lesions (46.9\%), followed by ulceropoliferative $(37.5 \%)$ and proliferative growth $(15.6 \%)$. Saha et al. ${ }^{15}$ had similar findings with ulcerative lesions most commonly (57.8\%) followed by ulceroproliferative $(24.9 \%)$ and polypoidal lesion (17.3\%). In the study by Kabir et al. ${ }^{11}$, ulcerative (56\%) was similarly the commonest growth followed by polypoidal (34\%) and ulceroinfiltrative (10\%) lesions.

Majority of these patients presented with Stage III carcinoma (46.8\%), followed by stage IV (25\%), stage II (18.8\%), and Stage I (9.4\%) in the present study. Most of the patients in the study by Barad et al. ${ }^{14}$ in India

\section{REFERENCES}

1. Thun MJ, DeLancey JO, Center MM, Jemal A, Ward EM. The global burden of cancer: priorities for prevention. Carcinogenesis. 2010;31(1):100-10. [PubMed | Full Text | $\underline{\mathrm{DOI}}]$ also presented in stage III (62.7\%). More than twothirds of the patients were diagnosed with advanced gastric cancer in a study in Iran. ${ }^{16}$ Patients presented with advanced Stages III followed by stage IV even in the studies by Isobe et al. ${ }^{17}$ in Japan and Park et al. ${ }^{18}$ in South Korea. All these studies suggest that patients with gastric carcinomas usually present late and with advanced stages in Asian countries.

The most common histological morphology was intestinal adenocarcinoma (56.3\%) in our study, consistent with other studies. ${ }^{14,18,19}$ Intestinal type adenocarcinoma was similarly the commonest histology and was seen in $55.9 \%$ by Eskandar et al. ${ }^{16}$, $53.6 \%$ by Saha et al. ${ }^{15}, 53 \%$ by Ghosh et al. ${ }^{7}$, and $52 \%$ by Kabir et al. ${ }^{11}$ Most $(61.1 \%)$ of the intestinal carcinoma were well to moderately differentiated whereas, most of the diffuse or mixed type tumors were poorly differentiated (71.4\%). Similar were the findings by Barad et al. ${ }^{14}$ All these studies suggest that patients with gastric adenocarcinomas usually present with advanced morphology and unfavorable histopathology.

This study had its limitations. It was a retrospective study with no follow-ups. Clinical presentation, operability, and clinical outcomes of gastric cancers were not studied. The study reflects the findings of a specific geographical area.

\section{CONCLUSIONS}

Gastric cancers are not uncommon findings in patients undergoing UGI endoscopies. They were commonly observed in patients aged more than 50 years of age. Antrum was the most common site. The majority presented with ulcerative growth on endoscopy and advanced stages in CECT abdomen with unfavorable histopathology. Thus, it is recommended that when alarming features and chronic symptoms are present, a delay should not be made for evaluation with upper GI endoscopy. Biopsy of the pathological lesions followed by histopathological confirmation must be done to rule out UGI tract malignancies.

\section{Conflict of Interest: None.}


sources, methods and major patterns in GLOBOCAN 2012. Int J Cancer. 2015;136(5):E359-86. [PubMed | Full Text | $\underline{\mathrm{DOI}}]$

4. Rahman R, Asombang AW, IbdahJA. Characteristics of gastric cancer in Asia. World J Gastroenterol. 2014;20(16):4483-90. [PubMed | Full Text | DOI]

5. Teh JL, Shabbir A, Yuen S, So JBY. Recent advances in diagnostic upper endoscopy. World J Gastroenterol. 2020;2 6(4):433-47. [PubMed | Full Text | DOI]

6. Shrestha U, Ghosh A, Alurkar VM, Kohli SC, Sapkota S. Prevalence of Helicobacter pylori infection, its correlation with gastroduodenal diseases and the incidence of gastric cancer in Nepal. Journal of Advances in Internal Medicine. 2013;2(2):52-60. [Full Text | DOI]

7. Ghosh A, Sathian B, Ghartimagar D, Narasimhan R, Talwar OP. Epidemiologic Analysis of Gastric Carcinoma in the Western Region of Nepal. Nepal Journal of Epidemiology. 2010;1(1):27-32. [Full Text | DOI]

8. Das A, Saha M, Shil BC, Yasmin R, Banik G, Salam M, et al. Clinical profile of patients presenting with carcinoma stomach in north-east district of Bangladesh. J MEDICINE. 2014;15:118-21. [Full Text | DOI]

9. Cherian JV, Sivaraman R, Muthusamy AK, Venkataraman J. Stomach carcinoma in the Indian subcontinent: A 16-year trend. Saudi J Gastroenterol. 2007;13(3):114-7. [PubMed | Full Text | DOI]

10. Debbarma A, Bhaumik A, Chowdhury B, Chakraborty P, Ghatak S, Sarkar SR. Prevalence of gastrointestinal tract cancer cases among population of Tripura: A histological study. IOSR Journal of Pharmacy and Biological Sciences. 2017;7(12):20-3. [Full Text]

11. Kabir MA, Barua R, Masud H, Ahmed DS, Islam MMSU, Karim E, et al. Clinical presentation, histological findings and prevalence of Helicobacter pylori in patients of gastric carcinoma. Faridpur Med. Coll. J. 2011;6(2):78-81. [Full Text [ DOI]

12. Quach DT, Ha DV, Hiyama T. The endoscopic and clinicopathological characteristics of early-onset gastric cancer in Vietnamese patients. Asian Pacific Journal of Cancer Prevention. 2018;19(7):1883-6. [PubMed | Full Text | $\underline{\mathrm{DOI}}]$

13. Mir SA, Intikhab M, Dar HM, Wani M. Clinico-pathological and demographic profile of patients with carcinoma stomach: a tertiary care experience. Int Surg J. 2019;6(6):2145- 9. [Full Text $\mid \underline{\text { DOI }}$

14. Barad AK, Mandal SK, Harsha HS, Sharma BM, Singh TS Gastric cancer: a clinic-pathological study in a tertiary care centre of North-eastern India. J Gastrointest Oncol. 2014;5(2):142-7. [PubMed | Full Text | DOI]

15. Saha AK, Maitra S, Hazra SC. Epidemiology of gastric cancer in the gangetic areas of west bengal. ISRN Gastroenterol. 2013 Oct 23;2013:823483. [․ㅏbMed | Full Text | DOI]

16. Eskandar H, Hossein SSM, Rahim M, Jalal H, Mehrdad A, Rajabi T. Clinical profile of gastric cancer in Khuzestan, southwest of Iran. World J Gastroenterol. 2006;12(30):4832-5. [PubMed | Full Text]

17. Isobe T, Hashimoto K, Kizaki J, Miyagi M, Aoyagi K, Koufuji $\mathrm{K}$, et al. Characteristics and prognosis of gastric cancer in young patients. Oncol Rep. 2013;30(1):43-9. [ㅁubMed | Full Text | DOI

18. Park JC, Lee YC, Kim JH, Kim YJ, Lee SK, Hyung WJ, et al. Clinicopathological aspects and prognostic value with respect to age: an analysis of 3,362 consecutive gastric cancer patients. J Surg Oncol. 2009;99(7):395-401. [릴ed | Full Text | DOI

19. Sambasivaiah K, Ibrarullah M, Reddy MK, Reddy PV, Wagholikar G, Jaiman S et al. Clinical profile of carcinoma stomach at a tertiary care hospital in south India. Trop Gastroenterol. 2004;25(1):21-6. [PubMed | Full Text]

This work is licensed under a Creative Commons Attribution 4.0 International License. The images or other third party material in this article are included in the article's Creative Commons license, unless indicated otherwise in the credit line; if the material is not included under the Creative Commons license, users will need to obtain permission from the license holder to reproduce the material. To view a copy of this license, visit http://creativecommons.org/licenses/by/4.0/ 